\title{
An Incidental Subepithelial Cecal Lesion
}

\author{
José Pedro Rodrigues $^{\mathrm{a}}$ Débora Correia $^{\mathrm{b}}$ Pedro Figueiredo $^{\mathrm{a}}$ \\ a Department of Gastroenterology, Centro Hospitalar Lisboa Ocidental, Hospital de Egas Moniz, Lisbon, Portugal; \\ ${ }^{b}$ Department of Surgery, Centro Hospitalar Lisboa Ocidental, Hospital de Egas Moniz, Lisbon, Portugal
}

\section{Keywords}

Quality in endoscopy · Mucocele · Appendiceal neoplasm ·

Subepithelial lesion

\section{Uma lesão subepitelial cecal incidental}

\section{Palavras Chave}

Qualidade em endoscopia $\cdot$ Mucocelo $\cdot$ Neoplasia do apêndice · Lesão subepitelial

Subepithelial colonic lesions are common findings at colonoscopy, mostly occurring in the rectum or cecum [1]. A presumptive diagnosis can frequently be made by the endoscopic appearance and the use of a biopsy forceps.
A 55-year-old asymptomatic female patient, with no relevant previous medical or family history, underwent a colorectal cancer screening colonoscopy which identified a $15-\mathrm{mm}$ smooth spherical bulge in the appendicular area of the cecum (Fig. 1). Tunnel biopsies were taken with translucent fluid drainage (Fig. 2). Subsequent histologic examination revealed the presence of colonic mucosa with no dysplasia and extracellular mucus. Physical examination was unremarkable, and no significant blood test abnormalities were found. Abdominal computed tomography scan was then performed showing appendicular wall thickening with isodense content and no lymphadenopathies or peritoneal implants. A laparoscopic right hemicolectomy was performed. A 24-cm surgical specimen including $9 \mathrm{~cm}$ of the terminal ileum and the ileocecal appendix was

Fig. 1. Spherical bulge in the appendicular area of the cecum (arrows).

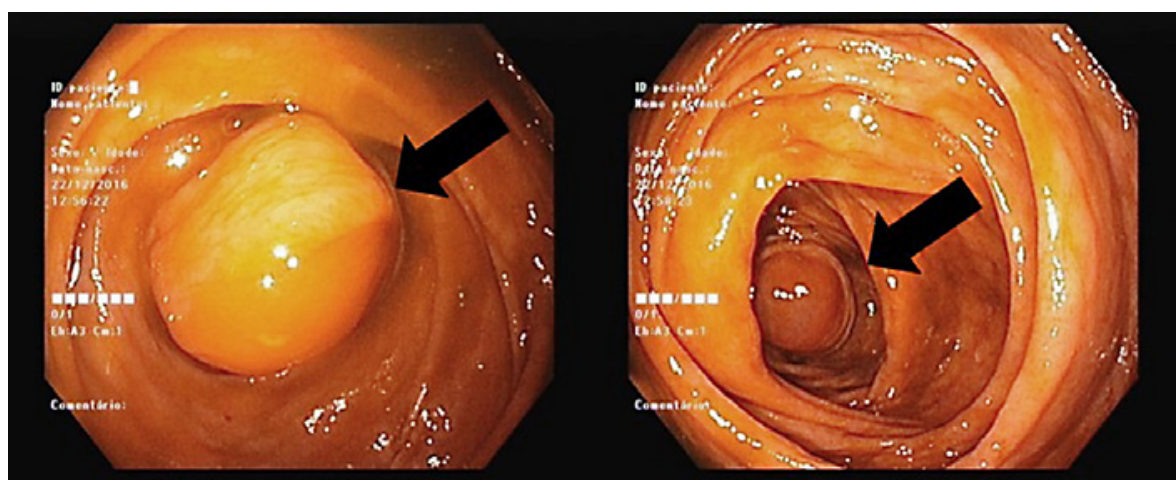

(C) 2018 Sociedade Portuguesa de Gastrenterologia Published by S. Karger AG, Basel

\section{Karger}

0 pen access

This article is licensed under the Creative Commons AttributionNonCommercial-NoDerivatives 4.0 International License (CC BYNC-ND) (http://www.karger.com/Services/OpenAccessLicense). Usage and distribution for commercial purposes as well as any distribution of modified material requires written permission.
Dr. José Pedro Rodrigues

Department of Gastroenterology, Centro Hospitalar Lisboa Ocidental Hospital de Egas Moniz

Rua da Junqueira 126, PT-1349-019 Lisbon (Portugal)

E-Mail jp.azevedo.rodrigues@gmail.com 
Fig. 2. Translucent fluid drainage after tunnel biopsies.

Fig. 3. Surgical specimen with a low-grade mucinous neoplasia involving the base and the middle third of the appendix (arrow).

\section{2}

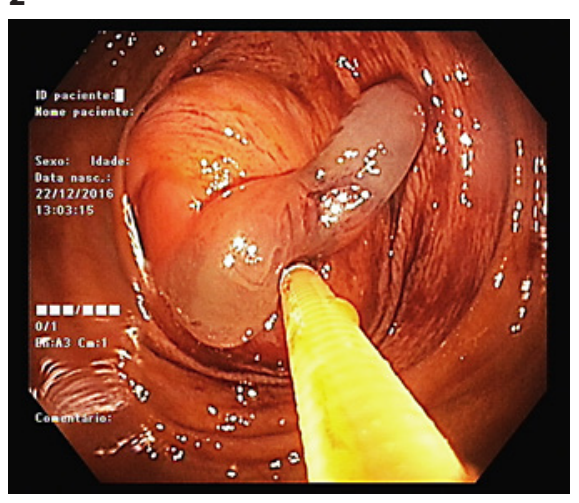

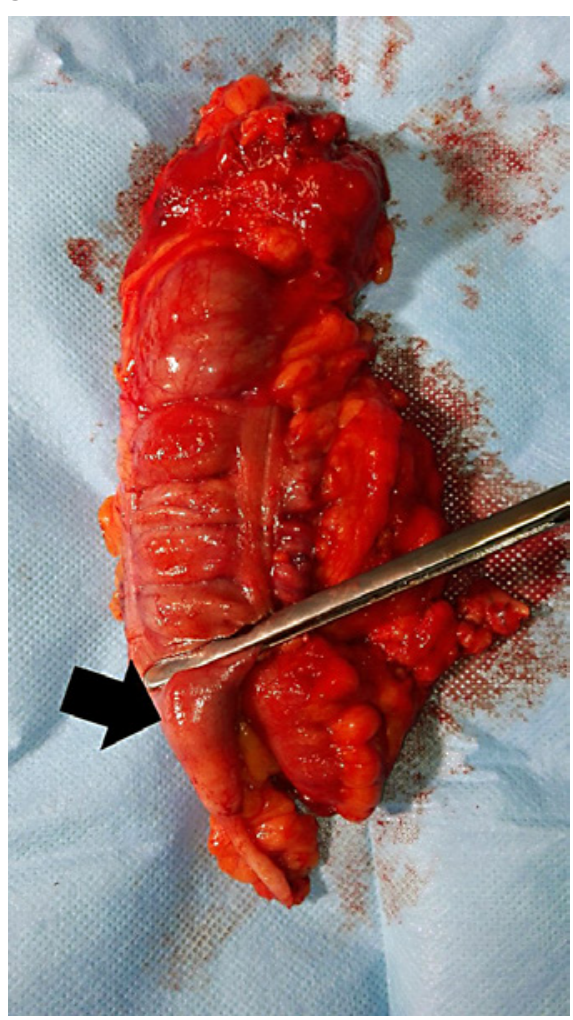

obtained (Fig. 3). Histological examination of the surgical specimen revealed the presence of low-grade mucinous neoplasia involving the base and the middle third of the appendix.

Mucinous neoplasms of the appendix are rare and represent a complex group of epithelial neoplasms often causing cystic dilation of the appendix due to accumulation of gelatinous material, morphologically referred to as mucoceles. Generally, they are incidentally diagnosed in asymptomatic patients [2]. The 2010 World Health Organization classification distinguishes between 3 main categories of this neoplasm: mucinous adenoma, low-grade appendiceal mucinous neoplasm, and appendiceal adenocarcinoma. For low-grade appendiceal mucinous neoplasm, which was present in this patient, certain features, such as the presence or absence of extra-appendiceal mucin, the location of mucin (confined to or spread beyond the right lower quadrant), or the presence of neoplastic cells outside the appendix, have prognostic significance [3]. In patients with favorable features, negative margin status, or normal serum levels of tumor markers, expectant management may be sufficient, although the follow-up approach is still open for consideration [4].

\section{Statement of Ethics}

This study did not require informed consent nor review/approval by the appropriate ethics committee.

\section{Disclosure Statement}

There are no conflicts of interest to declare.

References

1 Menon L, Buscaglia J: Endoscopic approach to subepithelial lesions. Therap Adv Gastroenterol 2014;7:123-130.

$\checkmark 2$ Tirumani SH, Fraser-Hill M, Auer R, et al: Mucinous neoplasms of the appendix: a current comprehensive clinicopathologic and imaging review. Cancer Imaging 2013;13: 14-25.

-3 Pai RK, Beck AH, Norton JA, et al: Appendiceal mucinous neoplasms: clinicopathologic study of 116 cases with analysis of factors predicting recurrence. Am J Surg Pathol 2009;33: 1425-1439.

4 Fournier K, Rafeeq S, Taggart M, et al: Lowgrade appendiceal mucinous neoplasm of uncertain malignant potential (LAMN-UMP): prognostic factors and implications for treatment and follow-up. Ann Surg Oncol 2017; 24:187-193.

Rodrigues/Correia/Figueiredo 